\title{
Mental illness in the family: an experiment in medical student teaching*
}

\author{
ANNE MCFADYEN, Senior Registrar, Child and Family Department, The Tavistock \\ Clinic, London NW3
}

\section{Background}

In $1987,38 \%$ of Royal Free medical students answered the question "How could the child psychiatry course be improved?" by asking for "more" - in particular, they wanted more "hands on" experience.

This is difficult for a number of reasons:

(a) the large student:teacher ratio,

(b) the length and nature of the attachment

(c) the students' inexperience. The handling of some child psychiatry problems demands considerable experience, expertise and sensitivity, but many students have had little prior contact with children either personally or professionally.

Our students do have the chance to see "live" families through the one-way screen but until recently their only "hands on" experience was in the form of a 'Communicating with Children' assignment, in which they would spend 20 minutes with a child (Sutton, 1986).

Child psychiatry teachers aim to promote the understanding of family functioning, and the effects of mentally and physically ill parents on child and family (Black, 1985). An attempt was recently made to address the above aims while at the same time giving students an opportunity for some 'hands on' experience.

\section{The task}

Students are attached in groups of two or three to an adult psychiatric firm where they clerk two or three patients per week during their eight-week block. The proposal that students could use the family of one of these patients as a focus for thinking about family functioning and the impact of one member's mental illness on other members of the family was introduced to students during a $1 \frac{1}{2}$-hour seminar entitled 'Mental Illness in the Family'. This was followed by three 40-minute group tutorials.

Students were first reminded of previous teaching on systems theory and family functioning and encouraged to think in terms of circular interaction

* Based on a paper presented at 'Teaching Child Psychiatry to Undergraduates' Conference, London, 1988. rather than in a linear fashion. The teacher involved them in a discussion about the relationship between mental illness and family functioning, taking ideas from them to create a 'map' of the system on the blackboard. The seminar leader contributed relevant additional theory. This 'brainstorming' session proved to be very fruitful, and at times provoked heated arguments between one student and another as well as between students and teacher about contentious issues such as attachment theory, child abuse and the aetiology of mental illness.

The genetic component of the functional psychoses in particular was taken as a foundation on which other ideas were built. For example, students were asked if they could imagine what it would be like to be the child of a schizophrenic mother, what influences the family might have on the patient's illness and what factors might contribute to a child being more or less vulnerable.

In the second part of the introductory seminar, a clinical case was presented to illustrate a number of points.

The 3-year-old child of a schizophrenic patient had been referred to the child psychiatrist by a paediatrician who was concerned about her developmental delay and promiscuous attachments. Mother lived with her parents and the little girl was subjected to the bizarre behaviour of both her mother and the maternal grandmother who was also schizophrenic.

Sequential video recordings of family interviews and in particular of mother-child interaction spanning a period of $2 \frac{1}{2}$ years from the time of her first referral were shown and discussed with the students.

The students' task - the preparation of a case study - was then explained in more detail. Students were given written guidelines, and asked to focus on two aspects of their presentation: a consideration of case dynamics; and the linking of theory and practice in the discussion. Key papers and references were made available. Possible tactics for obtaining the relevant clinical information, such as interviewing family members and home visits, were suggested. Students were encouraged to approach staff for individual discussion of their cases, and a handout summarising the initial 'brainstorming' session was distributed. 


\section{The students' responses}

Their initial response was enthusiastic as judged by the lively debate during the seminar. However, doubts and anxieties soon arose: "my patients are all geriatrics" said one: the implication seemed to be that they might not have families! Others expressed doubts about their ability to collect the right kind of information. A few were adamant that they would not learn anything.

A third of them sought individual help to think about the task, and most used the tutorials to propose hypotheses about the dynamics of their cases.

\section{The case studies}

Presentation was excellent in one-third and poor in another third. Most were much longer than the $1000-1500$ words requested. In the lower quality case studies, there was little structure and handwriting was often impossible to read.

Most students reviewed the literature adequately, and showed an ability to think clearly about the often complex case dynamics. However, many of the cases were presented from the perspective of the patient's family of origin, rather than the current one, and formulations were more often in terms of factors contributing to the illness and not the consequences of it. Many had difficulty in demonstrating an ability to think systemically.

Most of the cases were of schizophrenia or affective disorder; over a quarter of the patients reported sexual abuse during their childhood.

The case study which received the lowest mark seemed sparse in detail compared to the others, but did include one important heading - 'Interviewer's Reaction"- under which was written, "totally frustrated most of the time, I had the feeling that the patient was totally dominated by Id!"

A few were presented very fully, for example, one student considered the case of a 40-year-old depressed divorcee whose child was in the custody of her sister-in-law following abuse and neglect. Her ten year psychiatric history began with a puerperal psychosis; she had been repeatedly physically and sexually assaulted as a child and had great difficulty making and sustaining relationships.
Here was an explicit account of the transmission of abuse from one generation to the next. The student weaved her way through the patient's early separations, loss of father, rejection and abuse, managing to make some very important connections en route. She reviewed the literature on abuse, attachment theory and aetiology in an impressive way. She had clearly found the task interesting and put more than an adequate amount of work into it.

\section{Comment}

The introduction of this task was an experiment. The increase in staff workload required to supervise it will only be justified if it does provide an opportunity for the students to learn; if they simply perceive it as 'more work' then the aims will not be achieved. Our initial impression is that it does help students to think about family interaction and the effects of a mentally ill parent on the children and family's functioning. Although a number of students demonstrated that thinking, unfortunately, only a minority actually saw other members of the family, thus missing out on what might have been a greater 'hands on' experience.

\section{Acknowledgements}

Half way through the teaching block described, I suddenly remembered that as a student at Glasgow University I was required to do a 'family project' during the psychiatry block. There is no doubt that this made an impression on me at some level, and I thank Professor Bond and Dr Worrall, former Senior Lecturer.

I also thank Dr Dora Black for her support and encouragement.

\section{References}

BLACK, D. (1985) What medical students need to know about child psychiatry. Newsletter of the Association of University Teachers of Psychiatry, Summer, 12-16.

Sutton, A. (1986) Communicating with children. Beginning a new assignment for medical students. Paper presented at Teachers of Child Psychiatry Conference, June 1986. 